University of Texas Rio Grande Valley

ScholarWorks @ UTRGV

2015

\title{
Consumer Acceptance of Personal Cloud: Integrating Trust and Risk with the Technology Acceptance Model
}

\author{
Murad Moqbel \\ University of Texas Rio Grande Valley, murad.moqbel@utrgv.edu
}

Valerie L. Bartelt

Follow this and additional works at: https://scholarworks.utrgv.edu/is_fac

Part of the Business Commons, and the Computer Sciences Commons

\section{Recommended Citation}

Moqbel, Murad A. and Bartelt, Valerie L. (2015) "Consumer Acceptance of Personal Cloud: Integrating Trust and Risk with the Technology Acceptance Model," AIS Transactions on Replication Research: Vol. 1 , Article 5. DOI: 10.17705/1atrr.00005

This Article is brought to you for free and open access by the Robert C. Vackar College of Business \& Entrepreneurship at ScholarWorks @ UTRGV. It has been accepted for inclusion in Information Systems Faculty Publications and Presentations by an authorized administrator of ScholarWorks @ UTRGV. For more information, please contact justin.white@utrgv.edu,william.flores01@utrgv.edu. 


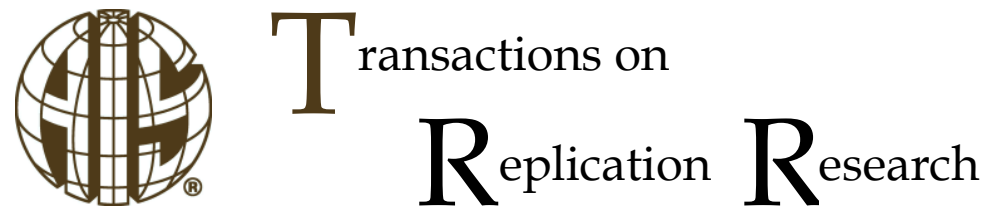

Conceptual Replication

ISSN 2473-3458

\section{Consumer Acceptance of Personal Cloud: Integrating Trust and Risk with the Technology Acceptance Model}

\author{
Murad A. Moqbel \\ Health Information Management \& Health Informatics \\ Departments \\ University of Kansas Medical Center \\ mmoqbel@kumc.edu
}

\author{
Valerie L. Bartelt \\ Department of Management, Marketing, and Information \\ Systems \\ Texas A\&M University - Kingsville \\ valerie.bartelt@tamuk.edu
}

\begin{abstract}
:
This paper conducts a conceptual replication of Pavlou (2003) which studied factors that impacted consumer's behavioral intentions to make online transactions by integrating trust and perceived risk with the technology acceptance model (TAM). We test the generalizability of the model by replicating the study a decade later using a different online setting-personal cloud computing. Our results that are based on 240 observations, confirm the original study's research model except perceived ease of use lost its direct predictive power to trust, perceived risk and perceived usefulness. Trust continues to be an important factor in perceived ease of use and perceived usefulness and should be an area of focus in online marketing strategies. Perceived usefulness continued to have a significant relationship for consumer's intentions to use, but perceived ease of use did not affect consumer's intention to use. Thus, more online businesses should focus on the usefulness of their service(s). Future studies are encouraged to methodologically replicate this study in different contexts and after another period in time to examine whether results hold.
\end{abstract}

Keywords: Replication, Personal Cloud, Technology-Oriented, Trust, Perceived Risk, Conceptual Replication

The manuscript was received 03/16/2015 and was with the authors 1 month for 1 revision. 


\section{Introduction}

The importance of the original research, in addition to the replication study, lies in the continually growing and changing online services. Since the original research was conducted in 2003, online services have drastically grown in importance. Currently it is becoming the norm for brick-and-mortar businesses to have an online presence. Additionally, many businesses are opting solely for an online presence. Not only is the replication research important for suggesting best practices when designing and promoting online services, but it is also important for determining whether the theoretical foundation of theory of reasoned action (TRA) and the technology acceptance model (TAM) still apply as a basis for intention to use online services. Thus, this replication research is relevant for both practitioners and researchers.

In regards to technology acceptance and use, the TAM model has been used for online use (Moon \& Kim, 2001; Van der Heijden, 2003). Perceived usefulness and perceived ease of use have been found to influence website use, as well as online transactions (Pavlou 2003). According to TRA, beliefs shape attitudes, which then affect behavioral intentions. Consumer intentions have been related to TRA, including in Pavlou's (2003) original research (Pavlou, 2003; Sheppard, Hartwick, \& Warshaw, 1988). This replication research, though intended to support the original study that TAM and trust and risk factors influence consumer intentions and behavior online, found that all factors held true across time and differing contexts except ease of use had no significant effect on intention to use.

\subsection{Overview of Original Research}

Pavlou's 2003 research on consumer acceptance, which integrated trust and perceived risk with TAM, found trust and risk to affect intentions to make online transactions. Trust was found to both directly affect intentions to transact and indirectly through perceived risk, perceived ease of use and perceived usefulness. Also perceived ease of use and perceived usefulness affected transaction intentions. Intentions to transact led to actual transaction. Our replication research in personal cloud computing is shown in Figure 2.

\subsection{Overview of Replication Research}

In addition to generalizability over time, this paper is interested in the generalizability of the Pavlou's 2003 research in the context of other online services. This replication study chose personal cloud computing to determine its generalizability in this context. Since the online market has been rapidly growing over the past years, more capabilities are now available on the internet, including storing data in an online environment, otherwise known as personal cloud computing. Personal cloud computing is growing in popularity as users are choosing to store their personal data onto online platforms (lon, Sachdeva, Kumaraguru, \& Čapkun, 2011). During personal cloud computing users upload their data onto the cloud environment, such as Dropbox, Skydrive, and Google Drive, enabling them to access the data on various computers, in addition to allowing them to collaborate and share the data with others (Gashami, Chang, Rho, \& Park, 2014).

Similar to e-commerce, both privacy risk and trust uncertainties have been identified in cloud computing (Pearson \& Benameur, 2010). Although personal cloud computing services are growing, there is a lack of research particularly in the area of privacy risks (Gashami et al., 2014). Privacy risks in cloud computing involve uncertainty in the degree of control of the user's sensitive data (lon et al., 2011), which is similar to the uncertainty in the degree of control of the user's sensitive data during online transactions. In both circumstances, the users agree to submit personal data onto the internet with the anticipation that the risk will be minimal.

Trust is also an important factor in personal cloud computing use (Pearson, 2013; Widjaja \& Chen, 2012). Popularity of the service and the number of users both were found to affect a user's trust and ultimate use of personal cloud (Kim \& Yoon, 2012). It is arguable that these same factors affect consumers' trust and ultimate use during online transactions. It makes sense that a popular online transaction site like Amazon affects a user's trust due to the popularity of the service and the numbers of users making transactions on the site. Thus, we believe that a replication study using a similar online setting, such as personal cloud computing, will determine the potential generalizable TAM and TRA factors from the original research. 


\subsection{Control Variables}

Similar to the original research, the replication research controlled for satisfaction. Since the context for replication was personal cloud, reputation was not controlled for due to the few number of personal cloud computing services available and all having a similar reputation. In lieu of frequency, familiarity was used to control for potential variability between users who are very familiar with personal cloud services and those who are not.

The original research hypotheses along with the results are illustrated in the research model in Figure 1.

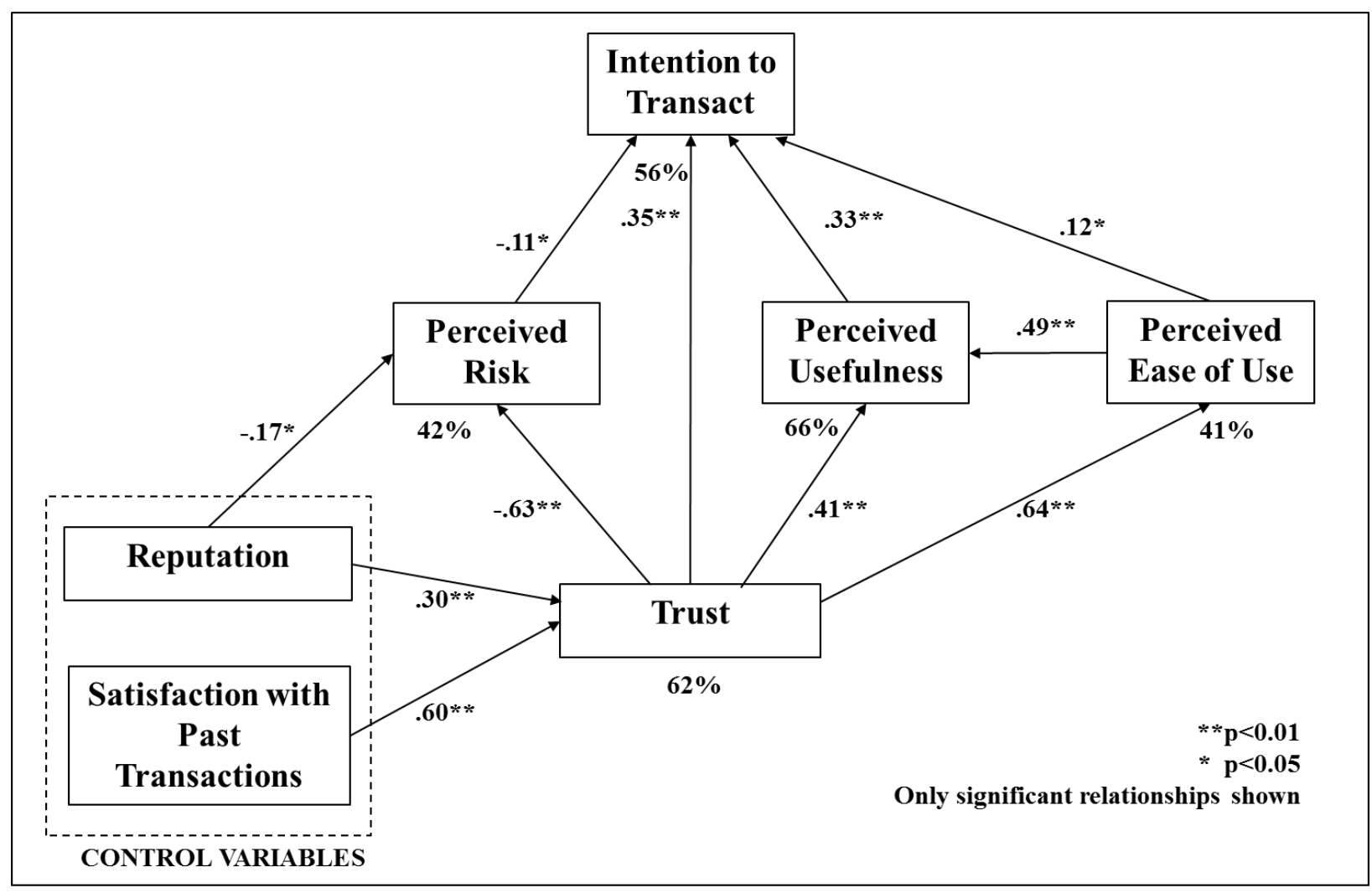

Figure 1. Research hypotheses and related results of the replicated study 


\section{Research Method}

To test our research model, we collected data from students in two universities in the Southwestern region of Texas. All constructs were adopted or adapted from existing literature. The measures for perceived ease of use and usefulness were adopted from validated prior studies (Venkatesh \& Morris, 2000; Wu \& Wang, 2005). The scales for trust, perceived risk, and familiarity were adapted from Gefen, Karahanna, and Straub (2003). The intention to use scales were adopted from Agarwal and Karahanna (2000) and Davis et al. (1992). Satisfaction with personal cloud scales were adapted from Bhattacherjee (2001).

All latent variables in the research instrument used seven-point Likert scale ranging from $1=$ strongly disagree, 2 = moderately disagree, 3 = slightly disagree, $4=$ neutral, $5=$ slightly agree, $6=$ moderately agree, to 7 = strongly agree.

A total of 240 completed questionnaires were obtained from the students. The following control variables were collected: age, sex, educational level, race, employment status, and work experience. Females contributed $55.8 \%$ of the responses. The average age of the respondents was 23.7 years, with a standard deviation of 8.44 years. The majority of respondents were Hispanic (65\%), followed by white (26\%), and other $(9 \%)$. In terms of educational level, $18.75 \%$ of the respondents had only completed high school, $20.42 \%$ had a 2 -year college degree, $51.25 \%$ had a 4 -year college degree, $5 \%$ had a master's degree, $2 \%$ had a doctoral degree, and $2.5 \%$ were missing. In terms of employment status, $20 \%$ of the respondents were employed full time, $49 \%$ were employed on a part-time basis, and $31.3 \%$ were unemployed and other. The average work experience was 5.6 years.

\subsection{Measurement Validation}

The data was analyzed using partial least squares structural equation modeling. In particular, we employed WarpPLS 5.0 to assess the measurement and the structural models (Kock, 2014).

To validate our measurement instrument, we performed factor analysis and then assessed the convergent and discriminant validity. We assessed convergent validity by examining the standardized item loadings which were all greater than the recommended threshold of 0.7 (Gefen, Straub, \& Boudreau, 2000).

We also examined Cronbach's alpha and composite reliability. Table 1 shows that all constructs exceeded the recommended reliability threshold of 0.7 (Gefen et al., 2000).

\begin{tabular}{|c|c|c|c|c|c|c|c|c|c|}
\hline \multicolumn{10}{|c|}{ Table 1: Reliability Coefficients for Each Construct } \\
\hline & TRUST & RISK & INTENT & PU & PEU & FAM & SAT & CA & CR \\
\hline TRUST1 & $(0.839)$ & 0.048 & 0.136 & -0.087 & -0.064 & 0.030 & -0.009 & \multirow{4}{*}{0.866} & \multirow{4}{*}{$0.90 s$} \\
\hline TRUST2 & $(0.807)$ & -0.065 & -0.017 & -0.064 & 0.089 & -0.105 & -0.034 & & \\
\hline TRUST3 & $(0.856)$ & 0.044 & -0.126 & 0.033 & 0.029 & 0.097 & 0.048 & & \\
\hline TRUST4 & $(0.876)$ & -0.030 & 0.008 & 0.110 & -0.050 & -0.027 & -0.007 & & \\
\hline RISK1 & -0.030 & $\begin{array}{l}(0.822) \\
\end{array}$ & -0.035 & 0.153 & 0.057 & -0.029 & -0.023 & \multirow{4}{*}{0.894} & \multirow{4}{*}{0.926} \\
\hline RISK2 & 0.026 & $(0.897)$ & 0.070 & -0.114 & -0.023 & 0.018 & 0.053 & & \\
\hline RISK3 & 0.026 & $(0.907)$ & 0.000 & -0.123 & -0.040 & 0.110 & -0.016 & & \\
\hline RISK4 & -0.027 & $(0.858)$ & -0.040 & 0.102 & 0.012 & -0.107 & -0.016 & & \\
\hline INTENT1 & 0.009 & -0.043 & $(0.901)$ & -0.193 & 0.099 & -0.172 & 0.005 & \multirow{3}{*}{0.824} & \multirow{3}{*}{0.896} \\
\hline INTENT2 & -0.070 & 0.101 & $(0.768)$ & 0.244 & -0.080 & 0.288 & -0.005 & & \\
\hline INTENT3 & 0.050 & -0.043 & $(0.909)$ & -0.015 & -0.031 & -0.073 & 0.000 & & \\
\hline PU1 & -0.027 & -0.067 & -0.031 & $(0.880)$ & 0.120 & 0.050 & -0.031 & \multirow{5}{*}{0.940} & \multirow{5}{*}{0.954} \\
\hline PU2 & -0.002 & 0.017 & -0.046 & $(0.934)$ & 0.032 & -0.050 & -0.042 & & \\
\hline PU3 & 0.000 & 0.001 & -0.018 & $(0.914)$ & -0.084 & -0.051 & -0.069 & & \\
\hline PU4 & 0.026 & 0.027 & -0.046 & $(0.921)$ & -0.142 & 0.040 & 0.048 & & \\
\hline PU5 & 0.003 & 0.021 & 0.153 & $(0.839)$ & 0.086 & 0.015 & 0.102 & & \\
\hline PEU1 & -0.031 & -0.020 & -0.045 & -0.013 & (0.927) & -0.075 & 0.022 & \multirow{3}{*}{0.925} & \multirow{3}{*}{0.952} \\
\hline PEU2 & 0.032 & 0.037 & 0.030 & -0.024 & $(0.938)$ & -0.014 & -0.011 & & \\
\hline PEU3 & -0.002 & -0.017 & 0.015 & 0.037 & $(0.933)$ & 0.089 & -0.011 & & \\
\hline FAM1 & 0.037 & -0.056 & -0.061 & -0.017 & 0.052 & $(0.884)$ & -0.013 & \multirow{3}{*}{0.847} & \multirow{3}{*}{0.907} \\
\hline FAM2 & 0.010 & 0.060 & 0.088 & 0.064 & -0.020 & $(0.881)$ & -0.058 & & \\
\hline FAM3 & -0.048 & -0.004 & -0.028 & -0.048 & -0.033 & $(0.859)$ & 0.072 & & \\
\hline SAT1 & 0.056 & -0.037 & -0.017 & 0.226 & 0.111 & 0.161 & $(0.781)$ & \multirow[b]{2}{*}{0.887} & \multirow[b]{2}{*}{0.923} \\
\hline SAT2 & -0.028 & 0.051 & 0.038 & 0.045 & -0.034 & -0.046 & $(0.917)$ & & \\
\hline
\end{tabular}




\begin{tabular}{|l|l|l|l|l|l|l|l|l|}
\hline SAT3 & 0.018 & -0.050 & 0.025 & -0.204 & 0.046 & -0.042 & $(0.883)$ & \\
\hline SAT4 & -0.038 & 0.030 & -0.050 & -0.043 & -0.109 & -0.053 & $(0.876)$ & \\
\hline
\end{tabular}
- TRUST = trust in personal cloud; RISK = perceived risk; INTENT= intention to use personal cloud; PEU =
perceived ease of use; PU= perceived usefulness; FAM = familiarity with personal cloud; SAT = satisfaction with
personal cloud use.
- Loadings are shown within parentheses; loadings are not rotated and cross-loadings are oblique-rotated.
- CR = composite reliability coefficient for latent variable.
- CA = Cronbach's alpha coefficient for latent variable.

We assessed the discriminant validity by comparing the square root of the average variance extracted (AVE) for each construct (in diagonal) with the correlations with other constructs. Table 2 shows that the AVEs exceed the correlations between the construct and other constructs, hence, our measurement instrument has acceptable discriminant validity.

\begin{tabular}{|l|l|l|l|l|l|l|l|}
\hline \multicolumn{7}{|l|}{ Table 2. Correlation between Latent Variables and Square Roots of AVEs } \\
\hline & TRUST & RISK & INTENT & PU & PEU & FAM & SAT \\
\hline TRUST1 & $(0.845)$ & & & & & & \\
\hline RISK & -0.211 & $(0.871)$ & & & & & \\
\hline INTENT & 0.407 & -0.351 & $(0.862)$ & & & & \\
\hline PEU & 0.481 & -0.188 & 0.613 & $(0.898)$ & & & \\
\hline PU & 0.491 & 0.004 & 0.357 & 0.633 & $(0.933)$ & & \\
\hline FAM & 0.413 & 0.024 & 0.312 & 0.470 & 0.641 & $(0.875)$ & \\
\hline SAT & 0.415 & -0.193 & 0.459 & 0.589 & 0.458 & 0.347 & $(0.866)$ \\
\hline \\
$\quad-$ AVE = Average variance extracted. \\
- Square roots of AVEs are shown on diagonal within parentheses
\end{tabular}

We conducted a full collinearity test (Kock, 2014) to assess if mulitcollinearity is a threat in our model. Table 3 shows that the variance inflation factors for all constructs are less than the recommended threshold of 5 (Hair, Black, Babin, \& Anderson, 2010; Kline, 2005; Kock, 2014).

\begin{tabular}{|l|l|l|l|l|l|l|l|}
\hline \multicolumn{7}{|c|}{ Table 3. Variance Inflation Factors for All Variables } \\
\hline & TRUST & RISK & INTENT & PU & PEU & FAM & SAT \\
\hline VIF & 1.534 & 1.213 & 1.830 & 2.612 & 2.397 & 1.766 & 1.637 \\
\hline - Variance inflation factors (VIFs) obtained through a full collinearity test. \\
- A VIF lower than 5 suggests no collinearity between a variable and other variables. \\
\hline
\end{tabular}




\section{Results}

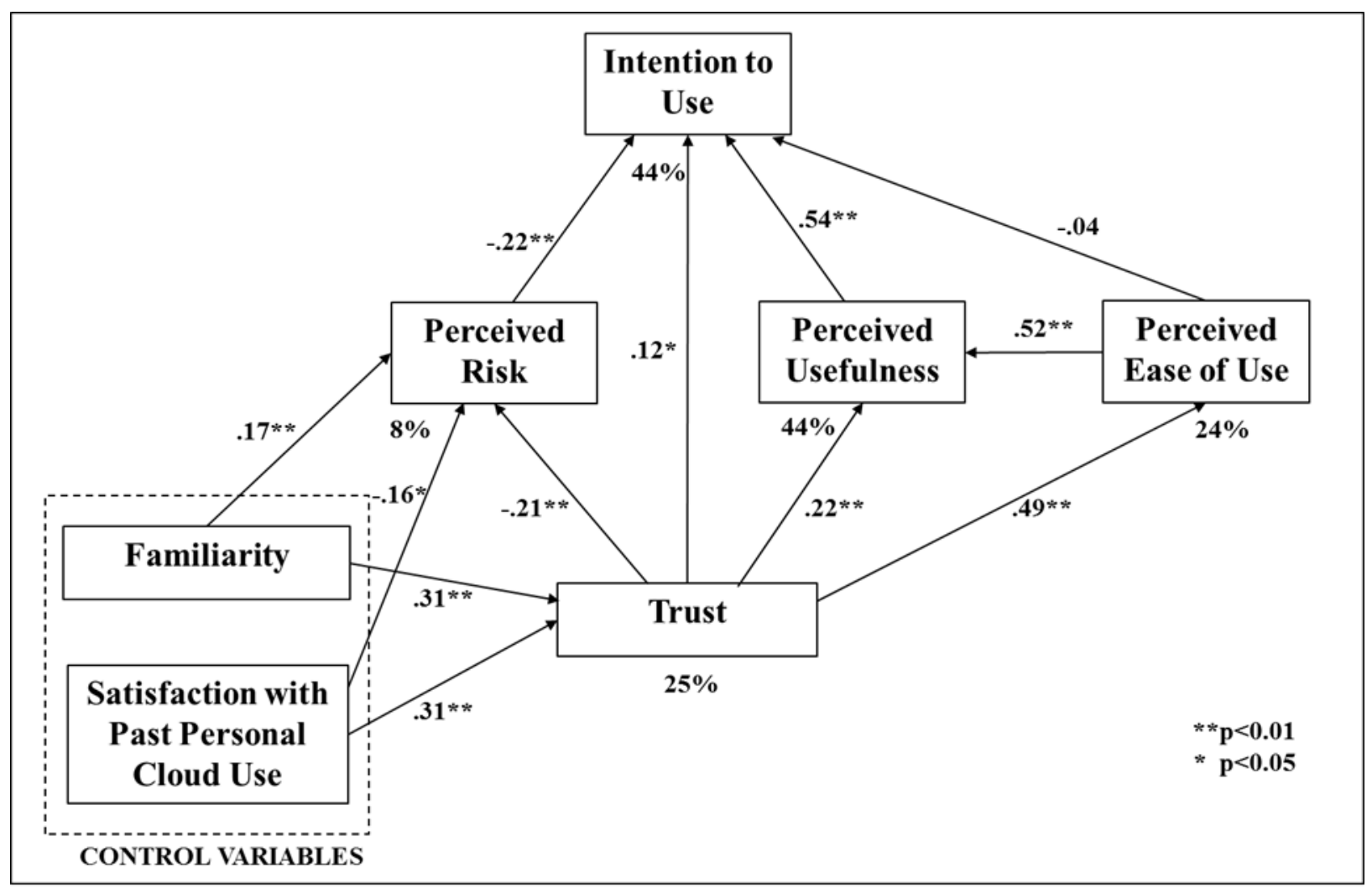

Figure 2. Research Hypotheses and Related Results

Model fit indices including Tenenhaus goodness of fit (GoF), average path coefficient (APC), average Rsquared (ARS), and average variance inflation factor (AVIF) all meet the recommended guidelines (Kock, 2014). Thus, Table 4 suggests that the structural model has an adequate fit with the data.

\begin{tabular}{|l|l|l|}
\hline \multicolumn{3}{|c|}{ Table 4. Model Fit Indices } \\
\hline Fit index & Value & Significance or acceptance level \\
\hline Tenenhaus GoF & 0.475 & Small $>=0.1$, Medium $>=0.25$, Large $>=0.36$ \\
\hline APC & 0.227 & $\mathrm{P}<0.001$ \\
\hline ARS & 0.285 & $\mathrm{P}<0.001$ \\
\hline AVIF & 1.372 & Good if $<5$ \\
\hline
\end{tabular}

The results indicate that trust in personal cloud vendors $(\mathrm{H} 1)$, perceived usefulness $(\mathrm{H} 2)$, and perceived risk (H5) had significant effects on intention to use personal cloud computing, explaining 44 percent of its variance. Perceived ease of use $(\mathrm{H} 4)$ and trust $(\mathrm{H} 6)$ had significant effect on perceived usefulness, explaining 44 percent of its variance. Trust had significant effects on perceived ease of use $(\mathrm{H} 7)$, explaining 24 percent of its variance. Trust $(\mathrm{H} 8)$ along with familiarity and satisfaction had significant effects on perceived risk; explaining eight percent of its variance. The control variables, familiarity, and satisfaction had significant effect on trust, explaining 25 percent of its variance. However, perceived ease of use $(\mathrm{H} 3)$ did not have significant effect on intention to use.

\section{Discussion}

The results of our replication research identified many similar results in comparison to the original Pavlou (2003) research. Trust remains an important factor, affecting, perceived risk, perceived ease of use, and perceived usefulness. Perceived risk continues to play a significant role in predicting intention to use. Consumers' consistency in responses between the two studies confirm the test of time in most of the theoretical foundations of TAM, TRA, and Pavlou (2003)'s model during online use. The consistency of perceived usefulness, risk, and trust on consumer's intention to use holds true in today's technological 
age. Perceived usefulness, risk, and trust affected intentions to use. Thus, our study generally supports the relevance of the original research, confirming generalizability of time and context.

The main difference identified in our replication research was in the area of consumer's intention to use on perceived ease of use. Differing from the original research, perceived ease of use did not affect consumer's intention to use $(\mathrm{H} 3)$. It is possible that today's consumers are more focused on the purpose of the website than navigation. Consumers seek online services that will complete an intended task. More plausibly, it may be due to the fact that users are growing more familiar with online services and therefore anticipate all sites to be easy to use. It is likely that today's users expect online services to be intuitive for getting the task done.

\subsubsection{Limitations and Implications for Future Research}

This conceptual replication research confirms the theoretical basis of TRA, TAM, and Pavlou (2003)'s integrated model over time in differing online service contexts. The original TRA theoretical findings from the original research hold true today. This replication study confirms the TRA theory that particular beliefs shape attitudes, which in turn affects behavioral intentions. As determined in H5, perceived risk were found to negatively affect consumer intentions to use personal cloud. This is still a viable concern among users' today that is likely pronounced by the heightened risk concerns due to recently publicized online data breaches during online use, increasing uncertainty issues. Additionally, H8 was supported that consumer's trust of personal cloud vendors negatively affects perceived risk. Risk is a viable online concern that our research confirms also affects other areas, including trust uncertainties.

Trust is an important area to monitor since it affects both perceived usefulness ( $\mathrm{H} 6)$ and perceived ease of use $(\mathrm{H} 7)$, which are consistent findings to the original research. Trust plays an essential role in determining whether an online service will be perceived as being useful and easy to use. As stated in the original research, if the components behind the website cannot be trusted, then it naturally follows that the website will not be considered useful (Pavlou, 2003). Additionally, users' trusting feelings toward an online service may help users to assume that it will be both intuitive to use and useful.

Concerning TRA theory, since the replication findings are consistent with the original research, more research is needed to tease out which type of risk is of more concern to users and under which circumstances. For instance, it is possible that security risks are equally of concern to all users, while privacy risks are mostly of concern to all users except for the younger millennial generation who grew up with an online presence. Additionally, since trust was an important factor affecting consumers' intention to use, more research is needed to explore potential factors that affect trust in online services, such as online vs. company reputation, product quality, online security, privacy, and online recommendations.

Confirming prior results with TAM, a consumer primarily chooses to use the site due to whether they think it will be useful in getting the task done. However, once the online service is perceived as useful, then perceived ease of use follows, as determined in $\mathrm{H} 4$. If an online service is considered useful, then the user navigates the site with purpose which may make the online website seem easier to use.

Concerning TAM, perceived usefulness affected consumer's intention to use, but not perceived ease of use. Thus, more research is needed to determine why perceived ease of use was not significant. We propose that this may be due to consumer's primary focus on website purpose versus navigation or that the expectations from today's users are that online services will be easy to use. More research is needed to determine whether either of these explanations hold true.

The contrary finding may also be due to the different online context in the replication research. The lack of predictive power of perceived ease of use might be user experience with personal cloud. In fact, user experience with the system was demonstrated to moderate the relationship between perceived ease of use and behavioral intention (Venkatesh \& Bala, 2008) such that more experienced users tend to not rely on ease of use in their decisions.

A replication of the research should be conducted in other online contexts to further confirm the generalizability of the research. Additionally, it is recommended that this research be replicated in another few years to determine whether factors affecting consumers' intention to use are consistent. It is possible that the factors may change as users' expectations change due to technological advances and increased comfortability with online services. 


\subsubsection{Implications for Businesses}

Concerning TRA theory, consumer's attitude and behaviors affect actions. Thus, online businesses should continue to find ways to alleviate issues dealing with the uncertainty risk. Consumers will have higher intentions to use online service when risk is minimized. Thus, online businesses should take additional security measures to minimize the risk involved with consumers using their online service(s), including uploading data and making online transactions. Since word travels fast in online platforms, it is especially important that each transaction involves minimal risk.

Since consumers' trust in personal cloud computing negatively affected perceived risk, online businesses should seek ways to increase trust perceptions related to online services. This may be as simple as adding information in the frequently asked questions section to clarify consumers' concerns with storing data and making transactions. For instance, confirming to customers that no personal information obtained and/or personal data stored will be provided to a third-party vendor. Additionally, a brief disclaimer on the front page of the site may ease initial consumers' concerns. Finding ways to nurture trust in an online environment is especially valuable since trust was found in both the original and replication study to affect perceived usefulness and perceived risk - which ultimately affected behavioral intentions to use online services.

Online businesses should be aware that trust is essential in facilitating consumers' usefulness perceptions. Consumers will not expect the site to be useful if those behind the website cannot be trusted (Gefen, 1997; Pavlou, 2003). Thus, gaining trust is an essential component that online businesses must possess. Although there may be temptations to take advantage of the personal data consumers are relinquishing, these temptations must be avoided in order to remain a trustworthy online business.

Similarly, trust is essential for facilitating the consumers' ease of use perceptions. If a consumer elicits trusting feelings toward an online company, then the user assumes that the site will be easy to use. Online businesses should take efforts to ensure they can be trusted to increase their consumers' useful and easy to use perceptions, ultimately affecting consumers' intentions to use.

The TAM model of perceived usefulness is consistent with prior research in affecting consumers' intention to use the online service; however contrary to the original research, consumers' perceived ease of use did not affect intention to use. Thus, online businesses should consider perceived usefulness as a fundamental component for online website usage. According to our findings, perceived ease of use takes a secondary role in online websites. If a person perceives a website as useful (primary), then it will be perceived as easy to use (secondary). It seems that the mind-over-matter, task-oriented website model wins in today's online businesses.

It is recommended that online businesses find ways to stress the usefulness of their online website. For instance, businesses should find ways to showcase how their online service(s) will help to streamline personal and/or work processes. Additionally usefulness should be an important criterion when implementing software interface upgrades. If a user is won over by the site's usefulness, then the ease of use is more likely to follow.

\section{Conclusion}

Much of the results of our replication research are similar in comparison to the original Pavlou (2003) research, confirming the validity of the original research. A majority of the theoretical framework established in Pavlou (2003) based on TAM and TRA holds true in online services after nearly a decade. Additionally, our findings are generalizable as the replication research extended the online transaction original research to the online cloud computing domain. Among other interesting findings, trust continues to play an important role in perceived ease of use, perceived risk, and perceived usefulness. Thus, online businesses need to take extra measures to ensure that they are trustworthy, to facilitate increasing consumers' useful and easy to use perceptions. This is particularly important since perceived usefulness was found to affect consumer's intention to use online services.

\section{References}

Agarwal, R., \& Karahanna, E. (2000). Time flies when you're having fun: cognitive absorption and beliefs about information technology usage. MIS Quarterly, 24(4), 665-694. 
Bhattacherjee, A. (2001). Understanding information systems continuance: an expectation-confirmation model. MIS Quarterly, 351-370.

Davis, F. D., Bagozzi, R., \& Warshaw, P. (1992). Extrinsic and intrinsic motivation to use computers in the workplace. Journal of Applied Social Psychology, 22(14), 1111-1132.

Gashami, J. P., Chang, Y., Rho, J. J., \& Park, M.-C. (2014). Understanding the trade-off between privacy concerns and perceived benefits in saas individual adoption. Paper presented at the Pacific Asia Conference on Information System, Chengdu, China.

Gefen, D. (1997). Building users' trust in freeware providers and the effects of this trust on users' perceptions of usefulness, ease of use and intended use of freeware: Georgia State University.

Gefen, D., Karahanna, E., \& Straub, D. W. (2003). Trust and TAM in online shopping: An integrated model. MIS Quarterly, 27(1), 51-90.

Gefen, D., Straub, D. W., \& Boudreau, M.-C. (2000). Structural equation modeling and regression: Guidelines for research practice. Communications of the Association for Information Systems, 4(1), 1-77.

Hair, J., Black, W., Babin, B., \& Anderson, R. (2010). Multivariate data analysis. Upper Saddle River, N.J.; London: Pearson.

Ion, I., Sachdeva, N., Kumaraguru, P., \& Čapkun, S. (2011). Home is safer than the cloud!: privacy concerns for consumer cloud storage. Paper presented at the Seventh Symposium on Usable Privacy and Security.

Kim, S., \& Yoon, Y. (2012). Elastic (E4C) Systems for Personal Learning Service in Smart Cloud. International Journal, 2(4), 116-121.

Kline, R. B. (2005). Principles and practice of structural equation modeling. New York: Guilford Press.

Kock, N. (2014). WarpPLS 5.0 user manual. Laredo, TX: ScriptWarp Systems.

Moon, J.-W., \& Kim, Y.-G. (2001). Extending the TAM for a World-Wide-Web context. Information \& Management, 38(4), 217-230.

Pavlou, P. A. (2003). Consumer acceptance of electronic commerce: Integrating trust and risk with the technology acceptance model. International Journal of Electronic Commerce, 7(3), 101-134.

Pearson, S. (2013). Privacy, security and trust in cloud computing Privacy and Security for Cloud Computing (pp. 3-42): Springer.

Pearson, S., \& Benameur, A. (2010). Privacy, security and trust issues arising from cloud computing. Paper presented at Second International Conference on the Cloud Computing Technology and Science (CloudCom), 2010 IEEE, Indianapolis, Indiana, USA.

Sheppard, B. H., Hartwick, J., \& Warshaw, P. R. (1988). The theory of reasoned action: A meta-analysis of past research with recommendations for modifications and future research. Journal of Consumer Research, 325-343.

Van der Heijden, H. (2003). Factors influencing the usage of websites: the case of a generic portal in The Netherlands. Information \& Management, 40(6), 541-549.

Venkatesh, V., \& Bala, H. (2008). Technology acceptance model 3 and a research agenda on interventions. Decision Sciences, 39(2), 273-315.

Venkatesh, V., \& Morris, M. G. (2000). Why Don't Men Ever Stop to Ask for Directions? Gender, Social Influence, and Their Role in Technology Acceptance and Usage Behavior. MIS Quarterly, 24(1), 115-139.

Widjaja, A., \& Chen, J. V. (2012). Using cloud computing service: A perspective from users' information security, privacy concern, and trust. Paper presented at the the 43rd Decision Sciences Institute Annual Meeting, San Francisco Marriot, San Francisco, CA.

Wu, J., \& Wang, S.-C. (2005). What drives mobile commerce?: An empirical evaluation of the revised technology acceptance model. Information \& Management, 42(5), 719-729. 


\section{Appendix A: Measurement Instrument}

The questions below were answered on a Likert-type scale ranging from " 1 - Very strongly disagree" to " 5 - Very strongly agree".

\section{Trust}

TRUST1: Based on my experience, personal cloud computing companies are honest

TRUST2: Based on my experience, personal cloud computing companies care about their customers

TRUST3: Based on my experience, personal cloud computing companies provide good service

TRUST4: Based on my experience, personal cloud computing companies are trustworthy

\section{Perceived Risk}

RISK1: In general, it would be risky to keep my personal information on personal cloud

RISK2: There would be high potential for loss associated with keeping personal information on personal cloud

RISK3: There would be too much uncertainty associated with keeping personal information on personal cloud

RISK4: Keeping my personal information on personal cloud would involve many unexpected problems

\section{Perceived Usefulness}

PU1: Using personal cloud computing tools would improve my performance

PU2: Using personal cloud computing tools would increase my productivity

PU3: Using personal cloud computing tools would enhance my effectiveness

PU4: Using personal cloud computing tools would make it easier for me to do my work

PU5: I think using personal cloud computing tools is very useful for me

\section{Perceived Ease of Use}

PEOU1: I think learning to use personal cloud computing tools is easy

PEOU2: I think becoming skillful at using personal cloud computing tools is easy

PEOU3: I think using personal cloud computing tools is easy

\section{Intention to Use}

INTENT1: I intend to continue keeping my personal information on personal cloud INTENT2: I plan continuing to use personal cloud to keep my files

INTENT3: I expect my keeping of personal information in the personal cloud to continue in the future

\section{Satisfaction}

How do you feel about your overall experience with personal cloud computing tools' use?

$\begin{array}{lllllllll}\text { SAT1: Very dissatisfied } & (1) & (2) & (3) & (4) & (5) & (6) & (7) & \text { Very satisfied } \\ \text { SAT2: Very displeased } & (1) & (2) & (3) & (4) & (5) & (6) & (7) & \text { Very pleased } \\ \text { SAT3: Very frustrated } & (1) & (2) & (3) & (4) & (5) & (6) & (7) & \text { Very contented } \\ \text { SAT4: Absolutely terrible (1) } & (2) & (3) & (4) & (5) & (6) & (7) & \text { Absolutely delighted }\end{array}$

\subsection{Perceived Familiarity}

FAM1: I am familiar with personal cloud computing (such as Dropbox).

FAM2: I know personal cloud computing because I use it.

FAM1: I am aware of cloud computing.

The additional questions below were not answered on a Likert-type scale.

- Gender: (Male/Female options were provided)

- Age

- Job Type: (Full-time/part-time)

- Years of Work Experience: (Leave Blank if Non-Applicable)

- Education: (High School, 2-year college, 4-year college, Master, Doctorate) 


\section{About the Authors}

Murad Moqbel is Assistant Professor of Health Information Management and Health Informatics at the University of Kansas Medical Center. He holds a Ph.D. degree in International Business Administration and Management Information Systems from Texas A\&M International University. He received both a B.S. degree with honors in Business Administration and Computer Information Systems and a MBA with Information Systems concentration from Emporia State University. He is in the editorial board of the International Journal of e-Collaboration and Information Processing \& Management Journal. He won best student paper award at the Southwest Decision Science Conference 2012. He has authored and coauthored several papers that appeared in: IEEE Transactions on Professional Communication Journal, Journal of Systems and Information Technology, Information Technology and People, AIS Transaction on Replication Research, International Journal of Virtual Communities and Social Networking, the proceedings of the International Conference in Information Systems (ICIS), and Americas Conference on Information Systems (AMCIS). His research interests focus on the interaction between human behavior and information technologies including social media, emerging technologies and Health IT, information security and privacy, and international business.

Valerie Bartelt is an Assistant Professor of Information Systems at Texas A\&M-Kingsville. She earned a Ph.D. in Information Systems and a M.S. in business from the Kelley School of Business, and a M.S. in Immersive Mediated Environments from telecommunications, all at Indiana University. Her work has been published in several journals including MIS Quarterly, Proceedings of the National Academy of Sciences, Journal of Management Information Systems, and Group Decision and Negotiation. Her research has also been noted in several media outlets including Reuters, Financial Times, The New York Times, Forbes, and Bloomberg. Her research interests primarily involve information communication technologies in virtual teams, neuro-IS, and issues surrounding technology use and adoption.

Copyright ( $) 2015$ by the Association for Information Systems. Permission to make digital or hard copies of all or part of this work for personal or classroom use is granted without fee provided that copies are not made or distributed for profit or commercial advantage and that copies bear this notice and full citation on the first page. Copyright for components of this work owned by others than the Association for Information Systems must be honored. Abstracting with credit is permitted. To copy otherwise, to republish, to post on servers, or to redistribute to lists requires prior specific permission and/or fee. Request permission to publish from: AIS Administrative Office, P.O. Box 2712 Atlanta, GA, 30301-2712 Attn: Reprints or via email from ais@aisnet.org. 